\title{
EVALUASI PENGGUNAAN ANTIBIOTIK PADA PASIEN PENYAKIT DIABETES MELITUS TIPE II DI INSTALASI RAWAT INAP RSU KARYA BAKTI UJUNG BANDAR RANTAUPRAPAT
}

\author{
Hartika Samgryce Siagian ${ }^{1}$, Casmada Harahap ${ }^{2}$ \\ Universitas Imelda Medan
}

\begin{tabular}{l}
\hline \hline Article Info \\
\hline Article history: \\
Received Mar 4, 2021 \\
Revised Mar 26, 2021 \\
Accepted Mar 29, 2021 \\
\hline
\end{tabular}

Keywords:

Type-2 Diabetes Mellitus Antibiotics

Rational.

\begin{abstract}
Diabetes Mellitus Type-2 is a disease characterized by abnormally low blood glucose levels or hyperglycemia due to insulin deficiency. Diabetes is a lifelong disease and one of the leading causes of death in the world. In the treatment of type 2 diabetes, antibiotics are needed. The rational use of antibiotics is needed to reduce endurance, disease severity, medical costs and length of treatment for type 2 diabetes sufferers. The aim of this study was to evaluate patient compliance with type 2 diabetes mellitus sufferers to the use of antibiotics in the Hospital inpatient section. Karya Bakti Ujung Bandar Rantauprapat Year 2019. This research used a descriptive method with retrospective data collection, data collection was carried out retrospectively from the medical record installation of diabetes mellitus patients in the Hospital Karya Bakti Ujung Bandar Rantauprapat Hospital in 2019. The results of the study on the rational distribution were based on exactly 50 patients (100\%). Right indication as many as 50 patients $(100 \%) .70$ prescriptions $(100 \%)$ and $100 \%$ correct dose.
\end{abstract}

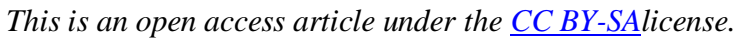

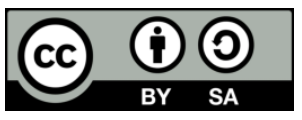

\section{Corresponding Author:}

Hartika Samgryce Siagian, Program Studi S1 Farmasi, Universitas Imelda Medan,

Jl. Bilal No. 52 Kelurahan Pulo Brayan Darat I Kecamatan Medan Timur, Medan - Sumatera Utara.

Email: hartikasiagian@gmail.com

\section{INTRODUCTION}

Diabetes Melitus (DM) ini adalah penyakit yang membutuhkan pengobatan jangka panjang atau bahkan seumur hidup. Diabetes dapat menyerang orang dari segala usia karena penyakit ini tidak hanya disebabkan oleh resistensi insulin, tetapi juga termasuk gaya hidup seperti kurang olahraga dan kebiasaan makan yang tidak sehat. Diabetes adalah keadaan dimana kadar gula darah melebihi kadar normal atau gula darah tinggi. Tubuh manusia sebenarnya memiliki cukup insulin untuk mengubah glukosa menjadi energi, tetapi insulin tidak dapat mengikat reseptornya, sehingga terjadi penumpukan glukosa di dalam darah.

DM merupakan salah satu penyakit yang menjadi masalah kesehatan dunia. Organisasi Kesehatan Dunia (WHO). DM Tipe 2 merupakan penyakit yg heterogen dengan banyak faktor yang mempengaruhinya, penyakit ini ditandai dengan adanya gangguan metabolic yaitu gangguan fungsi sel $\beta$ pankreas dan resistensi insulin di jaringan perifer seperti jaringan otot dan jaringan lemak, serta resitensi insulin di hati (Perkeni, 
2015). Hal ini mengakibatkan terjadinya hiperglikemia kronik dan dalam jangka panjang, dapat terjadi komplikasi yang serius. Resistensi insulin dianggap sebagai salah satu mekanisme yang mendasari diabetes tipe 2 (Merentek, 2006).

Tingginya kejadian diabetes, pentingnya penanganan diabetes yang benar dan komplikasi yang ditimbulkannya, pengobatan diabetes harus dilakukan secara wajar. Rasionalitas pengobatan meliputi ketepatan pengobatan, yang dipengaruhi oleh proses diagnosis, cara pengobatan, dan metode pengobatan. Evaluasi penggunaan obat merupakan proses penjaminan mutu yang terstruktur dan akan terus dilakukan untuk memastikan bahwa obat yang digunakan benar, aman dan efektif (Kumolosari, 2001).

Diabetes merupakan gangguan metabolisme yang dapat menyebabkan komplikasi mortalitas tinggi dalam keadaan darurat, oleh karena itu diperlukan penelitian untuk mengevaluasi rasionalitas diabetes tipe 2 (Kumolosari, 2001). Penggunaan antibiotik yang tidak tepat dapat menyebabkan resistensi terhadap antibiotik, dan efek pengobatan tidak sepenuhnya diberikan (Kuswandi, 2011). Ditunjukkan bahwa untuk mengobati infeksi diperlukan antibiotik yang dapat membunuh bakteri secara selektif. Jika antibiotik tidak dapat membunuh patogen, maka resistensi seks akan terjadi. Tidak mencapai efek terapi antibiotik (Kuswandi, 2011).

Berdasarkan latar belakang tersebut, peneliti ingin melakukan penelitian untuk mengetahui dan mengevaluasi kepatuhan pasien penderita penyakit DM (Diabetes Miletus) Tipe II terhadap pemberian obat antibiotik dengan menggunakan deskriptif tepat indikasi, tepat pasien, tepat dosis dan tepat obat di Rumah Sakit Umum Karya Bakti Ujung Bandar Rantau Prapat. Manfaat penelitian adalah untuk Meningkatkan wawasan dan pengetahuan tentang penyakit penderita DM Tipe II dan pengobatannya.

Tujuan Penelitian ini adalah:

1. Untuk mengetahui obat apakah yang banyak digunakan pada pasien penderita DM Tipe II di Instalasi Rawat inap Rumah Sakit Umum Karya Bakti Ujung Bandar Rantauprapat.

2. Untuk Mengetahui evaluasi penggunaan antibiotik pada pasien penderita DM Tipe II di Instalasi Rawat inap Rumah Sakit Umum Karya Bakti Ujung Bandar Rantau Prapat Tahun 2019 berdasarkan tepat indikasi, tepat pasien,tepat obat dan tepat dosis.

\section{RESEARCH METHOD}

Sampel adalah bagian sejumlah cuplikan penelitian yang diambil dari suatu populasi dan diteliti secara rinci (Pradana dan Reventiary, 2016) sampel pada penelitian ini adalah pasien DM Tipe-2 yang tercantum dalam rekam medik menggunakan terapi antibiotik di Instalasi Rawat Inap Rumah Sakit Karya Bakti Ujung Bandar Rantauprapat tahun 2019. Penelitian ini di lakukan di Rumah Sakit Karya Bakti Ujung Bandar Rantauprapat pengambilan data yang sudah terjadi ditahun 2019 direkam medik di Rumah Sakit Karya Bakti Ujung Bandar Rantauprapat.

\section{Alat dan Bahan}

Alat

Alat yang digunakan dalam penelitian adalah formulir pengambilan data yang dirancang sesuai dengan kebutuhan penelitian, seperti alat tulis untuk mencatat data.

\section{Bahan}

Bahan yang digunakan adalah data-data rekam medik (medical record) pasien DM Tipe-2 rawat inap din Rumah Sakit Karya Bakti Ujung Bandar Rantauprapat. Data dicatat pada lembar pengumpulan data meliputi nomor rekam medik, identitas pasien (jenis kelamin dan usia), diagnosa, antibiotik untuk pasien demam tifoid yang diberikan, tanggal masuk rumah sakit, tanggal rumah sakit, dan lama rawat inap.

Data yang diperoleh dianalisis dengan metode deskriptif yaitu non eksperimental dan kemudian diolah, untuk mengetahui rasionalitas penggunaan antibiotik pada pasien DM Tipe-2 di Rumah Sakit Karya Bakti Ujung Bandar Rantauprapat tahun 2019 dan hasil dievaluasi rasionalitasnya berdasarkan standar pengobatan sehingga persentase rasionalitas penggunaan antibiotik di Rumah Sakit Karya Bakti Ujung Bandar Rantauprapat 2019 dapat diketahui.

\section{RESULTS AND ANALYSIS}

\section{Distribusi Pasien Berdasarkan Dengan Jenis Kelamin}

Pengelompokan pasien berdasarkan jenis kelamin bertujuan untuk mengetahui jenis kelamin mana yang banyak terjadi kasus Diabetes Melitus Tipe-2 seperti yang terlihat pada tabel berikut: 
Tabel 1. Karakteristik Pasien Diabetes Melitus Tipe-2 di Rumah Sakit Umum Karya Bakti Ujung Bandar Rantauprapat Tahun 2019 Berdasarkan Jenis Kelamin

\begin{tabular}{cccc}
\hline No & Karakteristik & Frekuensi & Persentase \% \\
\hline 1 & Laki-laki & 16 & 32 \\
\hline 2 & Perempuan & 34 & 68 \\
\hline & Jumlah & $\mathbf{5 0}$ & $\mathbf{1 0 0}$
\end{tabular}

Berdasarkan tabel 1 diatas distribusi pasien dengan jenis kelamin di Rumah Sakit Karya Bakti Ujung Bandar Rantauprapat Tahun 2019 didapatkan hasil 16 pasien laki-laki (32\%) dan 34 pasien perempuan (68\%), dari tabel diatas dapat dilihat bahwa terdapat perbedaan angka yang begitu jauh berbeda mengenai kejadian Diabetes Melitus Tipe-2 pasien laki-laki dan perempuan. Penelitian ini dapat menunjukkan bahwa pasien perempuan lebih banyak menderita Diabetes Melitus Tipe-2 dibandingkan pasien laki-laki.

\section{Distribusi Pasien Berdasarkan Umur}

Tabel 2. Distribusi Pasien Diabetes Melitus Tipe-2 di Rumah Sakit Umum Karya Bakti Ujung Bandar Rantauprapat Tahun 2019 Berdasarkan Umur

\begin{tabular}{cccc}
\hline No & Umur & Jumlah Pasien & Persentase (100\%) \\
\hline 1 & $39-55$ & 17 & 34 \\
\hline 2 & $57-65$ & 24 & 48 \\
\hline 3 & $66-74$ & 9 & 18 \\
\hline & Jumlah & $\mathbf{5 0}$ & $\mathbf{1 0 0}$ \\
\hline
\end{tabular}

Berdasarkan tabel 2 diatas menunjukkan bahwa pasien penderita Diabetes Melitus Tipe-2 dapat diklasifikasikan berdasarkan umur 57-65 tahun adalah umur yang paling banyak terkena diabetes melitus tipe-2 yaitu 24 pasien (48\%) umur 39-55 tahun adalah umur kedua yang terkena diabetes melitus tipe-2 yaitu 17 pasien $(34 \%)$ dan yang terakhir umur 66-74 tahun yaitu 9 pasien (18\%). Diusia 55 tahun keatas banyak yang menderita diabetes melitus dikarenakan pada usia tersebut terjadi proses penuaan menyebabkan penurunan dan resistensi insulin sehinga pengendalian glukosa darah yang tinggi kurang optimal. Hal ini dapat menyebabkan proses makroangiopati yang mempengaruhi penurunan sirkulasi darah seperti pembuluh darah besar dan sedang, selain itu terjadi intoleransi glukosa khususnya kemampuan dan sel $\beta$ pada metabolisme glukosa untuk peroduksi insulin (Pangeman, 2014).

\section{Distribusi Pasien Berdasarkan Lama Inap (LOS)}

Pengolompokan distribusi pasien berdasarkaan lama rawat inap bertujuan untuk mengetahui berapa lama rata-rata rawat inap tiap pasien di rawat inap Rumah Sakit Umum Karya Bakti Ujung Bandar Rantauprapat Tahun 2019, seperti yang terlihat pada tabel berikut.

Tabel 3. Distribusi pasien diabetes melitus tipe-2 di Rumah Sakit Umum Karya Bakti Ujung Bandar

\begin{tabular}{cccc}
\multicolumn{4}{c}{ Rantauprapat Tahun 2019 } \\
\hline No & Lama Inap (LOS) & Frekuensi & Persentase \% \\
\hline 1 & 1 hari & 3 & 6 \\
\hline 2 & 2 hari & 4 & 8 \\
\hline 3 & 3 hari & 13 & 26 \\
\hline 4 & 4 hari & 14 & 28 \\
\hline 5 & 5 hari & 7 & 14 \\
\hline 6 & 6 hari & 8 & 16 \\
\hline 7 & 7 hari & 1 & 2 \\
\hline & Jumlah & $\mathbf{5 0}$ & $\mathbf{1 0 0 \%}$ \\
\hline
\end{tabular}

Berdasar tabel 3 diatas menunjukkan lama rawat inap pasien diabetes melitus tipe-2 di Instalasi Rawat Inap Rumah Sakit Umum Karya Bakti Ujung Bandar Rantauprapat Tahun 2019. Semua dta rekam medik pasien diabetes melitus tipe-2 tersebut memenuhi kriteria inklusi. Prevalensi rawat inap tertinggi adalah 4 hari sebanyak 14 pasien dengan persentase 28\% dan yang tertinggi kedua yaitu 3 hari sebanyak 13 pasien dengan persentase $26 \%$ pasien yang diperbolehkan pulang dari rumah sakit karena kondisi pasien sudah sembuh atau melakukan rawat jalan dan dapat meneruskan terapi lanjutan dirumah karena sudah merasa lebih baik atau sembuh.

\section{Distribusi Pasien Diabetes Melitus Tipe-2 Berdasarkan Antibiotik Yang Digunakan}

Pengelompokan distribusi pasien berdasarkan antibiotik yang digunakan bertujuan untuk mengetahui jenis antibiotik yang paling banyak diresepkan dan digunakan oleh pasien diabetes melitus tipe-2 di instalasi rawat inap Rumah Sakit Umum Karya Bakti Ujung Bandar Tahun 2019 dapat di lihat pada tabel berikut: 
Tabel 4. Distribusi Pasien Diabetes Melitus Tipe-2 Di Rumah Sakit Umum Karya Bakti Ujung Bandar Rantauprapat Tahun 2019 Berdasarkan Penggunaan Antibiotik

\begin{tabular}{cccc}
\hline No & Nama antibiotik & Frekuensi & Persentase $\%$ \\
\hline 1 & Sefalosforin & Ceftriaxone & 29 \\
\hline 2 & Betalaktam & Meropenem & 8 \\
\hline 3 & Golongan lain & Metronidazole fls & 9 \\
\hline 4 & Golongan lain & Metronidazole tab & 5 \\
\hline 5 & Fluoroquinolon & Ciprofloxacin fls & 7 \\
\hline 6 & Fluoroquinolon & Ciprofloxacin tab & 4 \\
\hline 7 & & Cotrimoxazole tab & 2 \\
\hline 8 & Sefalosforin & Cefixime 200 mg & 6 \\
\hline & Jumlah & $\mathbf{7 0}$ & $\mathbf{1 0 0}$ \\
\hline
\end{tabular}

Data yang di peroleh terdapat 8 jenis antibiotik yang paling banyak diresepkan pada pasien diabetes melitus tipe-2 di instalasi rawat inap Rumah Sakit Karya Bakti Ujung Bandar Rantauprapat Tahun 2019. Ceftriaxone $=29(41 \%)$ dan metronidazole fls $=9(13 \%)$, merupakan antibiotik yang banyak digunakan dibandingkan dengan antibiotik yang lain. Antibiotik yang banyak digunakan berasal dari golongan sefalosforin (ceftriaxone dan cefixime) adalah golongan antibiotik yang paling banyak di gunakan di instalasi rawat inap di Rumah Sakit Karya Bakti Ujung Bandar Rantauprapat Tahun 2019.

\section{Kesesuaian Dengan Formularium Rumah Sakit}

Kesesuaian penggunaa antibiotik yang digunakan untuk terapi pasien diabetes melitus tipe-2 di Rumah Sakit Karya Bakti Ujung Bandar Rantauprapat Tahun 2019 dapat dilihat pada tabel berikut:

Tabel 5. Kesesuaian Antibiotik Dengan Formularium Rumah Sakit Kaya Bakti Ujung Bandar Rantauprapat Tahun 2019

\begin{tabular}{cccc}
\hline No & Hasil & Jumlah Resep & Persentase \% \\
\hline 1 & Ceftriaxone & $\sqrt{ }$ & - \\
\hline 2 & Cefixime & $\sqrt{ }$ & - \\
\hline 3 & Ciprofloxacin fls & $\sqrt{ }$ & - \\
\hline 4 & Ciprofloxacin tab & $\sqrt{ }$ & - \\
\hline 5 & Cotromoxazole tab & $\sqrt{ }$ & - \\
\hline 6 & Metronidazole fls & $\sqrt{ }$ & - \\
\hline 7 & Metronidazole tab & $\sqrt{ }$ & - \\
\hline 8 & Meropenem & $\sqrt{ }$ & $\mathbf{1 0 0}$
\end{tabular}

Tabel diatas disimpulkan bahwa kesesuaian antibiotik yang digunakan untuk pasien diabetes melitus di Rumah Sakit Karya Bakti Ujung Bandar Rantauprapat Tahun 2019 dengan formularium rumah sakit sangat sesuai. Artinya semua obat antibiotik yang telah digunakan di rumah sakit ada pada formularium.

\section{Evaluasi Ketepatan Penggunaan Antibiotik}

Tepat Indikasi

Setiap obat memiliki spektrum terapi yang spesifik. Misalnya antibiotik di indikasikan untuk penyakit akibat infeksi bakteri. Penggunaan antibiotik ini di dasarkan pada panduan informasi obat nasional 2015 yang dikeluarkan oleh BPOM RI. Pengobatan dikatakan sudah tepat indikasi apabila indikasi obat sesuai dengan penyakit yang diderita. Pada penelitian ini adalah penggunaan antibiotik berdasarkan adanya indikasi diabetes melitus tipe-2.

Tabel 6. Evaluasi Ketepatan Indikasi Penggunaan Antibiotik Pada Pasien Diabetes Melitus Tipe-2 Di Instalasi Rawat Inap Di Rumah sakit Karya Bakti Ujung Bandar Rantauprapat Tahun 2019

\begin{tabular}{cccc}
\hline No & Hasil & Jumlah Resep & Persentase \% \\
\hline 1 & Tepat indikasi & 70 & 100 \\
\hline 2 & Tidak tepat indikasi & 0 & 0 \\
\hline & Jumlah & $\mathbf{7 0}$ & $\mathbf{1 0 0}$ \\
\hline
\end{tabular}

Diketahui dari penelitian bahwa sebanyak 70 resep yaitu dengan persetase $100 \%$ sudah tepat indikasi. Antibiotik yang digunakan adalah ceftriaxone, cefixime, ciprofloxacin tab, ciprofloxacin fls, cotrimoxazole tab, metronidazole fls, metronodazole tab, meropenem. Dengan demikian semua antibiotik yang digunakan pada pasien diabetes melitus tipe-2 di instalasi rawat inap Rumah Sakit Jarya Bakti Ujung Bandar Rantauprapat Tahun 2019 Yaitu 100\% tepat indikasi. 


\section{Tepat Dosis}

Pemberian yang tidak tepat sangat berpenaruh terhadap efek terapi obat. Pemberian dosis yang berlebihan ataupun lama pemberiannya tidak sesuai dengan formularium, antibiotik yang diberikan dikatakan tidak tepat khususnya untuk obat yang dengan rentang terapi yang sempit akan sangat berisko timbulnya efek samping. Sebaliknya dosis yang terlalu kecil tidak dapat menjamin tingkat pengobatan yang dibutuhkan.

\section{Tepat Obat}

Obat yang sesuai adalah obat untuk pasien yang masuk dalam daftar obat yang dianjurkan. Dengan mempertimbangkan keamanan, daya aplikasinya dan efektivitasnya, maka dipilih obat yang harus mempunyai efek terapeutik sesuai penyakit yang diuderita.

Tabel 7. Evaluasi Ketepatan Penggunaan Obat Antibiotik Pada Pasien Diabetes Melitus Tipe-2 Di Rawat Inap Di Rumah Sakit Karya Bakti ujung Bandar Rantauprapat Tahun 2019

\begin{tabular}{cccc}
\hline No & Hasil & Jumlah Resep & Persentase \% \\
\hline 1 & Tepat obat & 70 & 100 \\
\hline 2 & Tidak tepat obat & 0 & 0 \\
\hline & Jumlah & $\mathbf{7 0}$ & $\mathbf{1 0 0}$
\end{tabular}

Tabel diatas diketahui sebanyak 70 resep yaitu $100 \%$ dari total keseluruhan resep dikatakan tepat obat, sedangkan resep yang dikatakan tidak tepat obat dinyatakan 0\%. Hal ini dikatakan pasien diabetes melitus tipe-2 di instalasi Rawat inap Rumah Sakit Karya Bakti Ujung Bandar Rantauprapat Tahun 2019 dikatakan tepat obat.

\section{Tepat Pasien}

Kesesuaian dan evaluasi pasien mencakup pertimbangan apakah terdapat kontraindikasi atau keadaan khusus yang memerlukan penyesuaian dosis individu.

Tabel 8. Evaluasi Ketepatan Pasien Penggunaan Antibiotik Pada Pasien Diare Pada Anak Dirawat Inap Rsu Karya Bakti Ujung Bandar Rantauprapat Tahun 2019

\begin{tabular}{cccc}
\hline No & Hasil & Jumlah Pasien & Persentase \% \\
\hline 1 & Tepat pasien & 50 & 100 \\
\hline 2 & Tidak tepat pasien & 0 & 0 \\
\hline & Jumlah & $\mathbf{5 0}$ & $\mathbf{1 0 0}$
\end{tabular}

Tabel diatas bahwa dari 50 pasien yaitu sebanyak 100\% pasien diabetes melitus tipe-2 di instalasi rawat inap Rumah Sakit Karya Bakti Ujung Bandar Rantauprapat Tahun 2019 dikatakan tepat pasien berdasarkan dengan diagnosis dokter. Antibiotik yang diberikan yaitu ceftriaxone, cefixime, cotrimoxazole, ciprofloxacin fls, ciprofloxacin tab, metronidazole fls, metronidazole tabdan meropenem tidak menimbulkan hipersensitivitas terhadap pasien yang menggunakan.

Dari penelitian ada kesesuaian yang dapat dilihat unruk penggunaan antibiotik pada pasien diabetes melitus tipe-2 di instalasi rawat inap Rumah Sakit Karya Bakti Ujung Bandar dengan penatalaksanaan diabetes melitus tipe-2 yaitu tepat indikasi, tepat pasien, tepat dosis dan tepat obat. Hasil dari evaluasi penggunaan antibiotik di instalasi rawat inap Rumah Sakit Karya Bakti Ujung Bandar Rantauprapat Tahun 2019 yang rasional berdasarkan kriteria.

\section{CONCLUSION}

Kesimpulan yang didapat berdasarkan penelitian ini adalah sebagai berikut:

1. Evaluasi penggunaan pada pengobatan diabetes melitus tipe-2 di instalasi rawat inap Rumah Sakit Umum Karya Bakti Ujung Bandar Rantauparapat Tahun 2019 didapatkan hasil kesesuaian formularium Rumah Sakit Karya Bakti Ujung Bandar Rantauprapat adalah 100\% tepat indikasi 70\%, tepat obat $70 \%$.

2. Penggunaan antibiotik pada pengobatan diabetes melitus tipe-2 di instalasi rawat inap Rumah Sakit Karya Bakti Ujung Bandar Rantauprapat Tahun 2019 sudah sesuai dengan standar keputusan Kementrian Kesehatan Tahun 2006.

\section{REFERENCES}

ADA. (2010). Diagnosis And Clasification Of Diabetes Care, 1 Januari 2014 Vol: 27.

BPOM, R. (2015). http://pionas.pom.go.id/ioni/. Jakarta: Kementrian Kesehatan RI.

Departemen Kesehatan Republik Indonesia. 2004. Kepmenkes No. 1197/MENKES/SK/X/2004Tentang Standar Pelayanan Farmasi Di Rumah Sakit. Jakarta: Depkes RI.

Departemen Kesehatan Republik Indonesia. 2005. Pharmaceutical Care Untuk Penyakit Diabetes Melitus. Jakarta: Depkes RI. 
Departemen Kesehatan Republik Indonesia. 2008. Permenkes No. 269/MENKES/PER/2008 Tentang Rekam Medis. Jakarta: Depkes RI.

Departemen Kesehatan RI. (2005). Pharmaceutical Care Untuk Penyakit Diabetes Militus. Jakarta: Direktorat bina Farmasi Komunitas dan Klinik.

Departemen Kesehatan RI. (2011). Peraturan Kementrian Kesehatan Mengenai Penggunaan Antibiotika. Jakarta: Departemen Kesehatan RI.

Fatimah, R.N. (2015). Diabetes Militus Tipe 2. J Majority, Vol 4

Gilman, G.A. (2012). Dasar Farmakologi Terapi, Ed 10. Jakarta: EGC.

Kartika, R. (2017). Pengelolaan Diabetes Melitus Countinuing Medical Education.

Kementrian Kesehatan RI. Modul Penggunaan Obat Rasional. Jakarta: Kementrian Kesehatan RI.

Kementrian Kesehatan RI. (2011). Pedoman Pelayanan Kefarmasian Untuk Terapi Antibiotik. Jakarta: Kementrian Kesehatan RI.

Kementrian Kesehatan RI. (2013). Riset Kesehatan Dasar. Jakarta: Pengembangan Kesehatan Kementrian Kesehatan RI.

Kementrian Kesehatan RI. (2011). Pedoman Umum Penggunaan Antibiotik. Jakarta: Kemenkes RI.

Marentek, E. Resistensi Insulin Pada Diabetes Tipe-2 Cermin Dunia Kedokteran 2006:150,

NIDDK, N, I. (2014). Cause of diabetes. New York: NIH publication,

Perkeni,. (2011). KONSESNSUS: Pengolaan dan Pencegahan Diabetes Militus Tipe 2 di Indonesia. Jakarta: Kementrian Kesehatan RI

Perkeni, P.E. (2015). Pengelolaan Dan pencegahan Diabetes Melitus Tipe 2 Di indonesia 2015. Jakarta: Pb.Perkeni.

Perkeni. (2011). Konsensus dan Pencegahan diabetes melitus tipe 2 di Indonesia. Jakarta: Perkeni.

Riskesdas. (2007). Riset Kesehatan Dasar 2007. Jakarta: Badan Pengembangan Kesehatan Kementrian Kesehatan RI.

Utami Rahayu E. 2011. Antibiotika, Resistensi ,dan Rasionalitas Terapi. Malang.

WHO. (2014). World Health Organization, 2014, Antimicrobial Resistence.http://www.who.int/mediacentre/factssheets/fs194/en/. American 